\title{
Does higher education properly prepare graduates for the growing artificial intelligence market? Gaps' identification using text mining
}

\author{
Lamiae Benhayoun* and Daniel Lang \\ Institut Mines Télécom Business School, LITEM, Evry Cedex, France
}

Received 5 February 2021

Accepted 29 April 2021

\begin{abstract}
.
BACKGROUND: The renewed advent of Artificial Intelligence (AI) is inducing profound changes in the classic categories of technology professions and is creating the need for new specific skills.

OBJECTIVE: Identify the gaps in terms of skills between academic training on AI in French engineering and Business Schools, and the requirements of the labour market.

METHOD: Extraction of AI training contents from the schools' websites and scraping of a job advertisements' website. Then, analysis based on a text mining approach with a Python code for Natural Language Processing.

RESULTS: Categorization of occupations related to AI. Characterization of three classes of skills for the AI market: Technical, Soft and Interdisciplinary. Skills' gaps concern some professional certifications and the mastery of specific tools, research abilities, and awareness of ethical and regulatory dimensions of AI.

CONCLUSIONS: A deep analysis using algorithms for Natural Language Processing. Results that provide a better understanding of the AI capability components at the individual and the organizational levels. A study that can help shape educational programs to respond to the AI market requirements.
\end{abstract}

Keywords: Artificial intelligence, data science, labour market, higher education, natural language processing, text mining, web scraping, skills

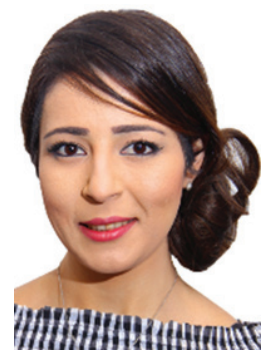

Lamiae Benhayoun is Associate Professor at Institut Mines Télécom Business School, France. She holds an engineering degree in Telecommunications and a double Ph.D. in Management Sciences and Automation Engineering. Her research interests include collaborative innovation and digital transformation, with a focus on knowledge management and maturity assessment. Dr. Benhayoun also strives to transfer academic knowledge to socio-economic actors through case studies' writing and the design of audit tools.

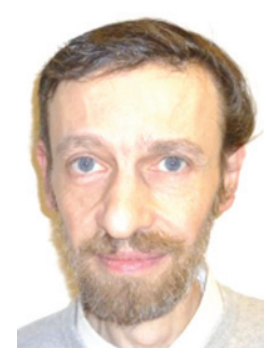

Daniel Lang is Assistant Professor at Institut Mines-Telecom Business School, France. He holds a Ph.D. in Computer Science. His main research interests include information systems, IT for education, Serious Games, process optimization and cybersecurity. Prior to joining the academic field, Dr. Lang worked for several years as an IS consultant in business process reengineering.

\footnotetext{
${ }^{*}$ Corresponding author: Lamiae Benhayoun, Institut Mines Télécom Business School, LITEM, 9, rue Charles Fourier, 91011, Evry Cedex, France. Tel.: +33 1607643 13; E-mail: lamiae.ben hayoun@imt-bs.eu. ORCID ID: 0000-0003-4183-7205
} 


\section{Introduction}

Business environments are increasingly turbulent with incessant technological advances and unpredictable customer behavior [1]. In this respect, firms in all industries are becoming more interested in the data they produce or can collect externally to improve their performance and align with market changes [2]. Indeed, the evolution of Information Technologies (IT) and the use of the Internet of Things (IoT) generates an enormous amount of data that companies are striving to exploit and make intelligible through Artificial Intelligence (AI) [3]. They are thus engaged in projects to design new approaches both in data processing and in organizational and managerial configurations [4] in order to fully integrate this new resource into their Information Systems [5]. AI has attracted both practitioners and researchers' attention in technical and human sciences over the last two decades [6]. It has grown enormously since 2010 thanks to the various data and computing power that did not exist before, and its development is still far from complete. By 2025, the AI market will be worth $\$ 90$ billion, compared to $\$ 7$ billion in 2018 [7].

$\mathrm{AI}$ is present in many areas and applications related to research and innovation such as financial systems, government decisions, medical sector, etc. Its renewed advent is inducing profound changes in the classic categories of IT professions and is creating the need for new specific skills, for instance in terms of data collection, data mining, or data quality management [8]. Indeed, a recent global survey conducted by IBM has concluded that in the next three years, approximately 120 million jobs will have to adapt to the advances in AI, and this only for the 10 most dynamic economies on the planet [9]. Therefore, it is wise to question whether academic institutions are aligned with the accelerated integration of $\mathrm{AI}$ in firms and thus whether they are properly preparing engineering and management students for the contemporary needs of the job market in terms of AI.

To answer this question gap, we mobilize a text mining approach enabling the analysis of job offers and academic training content in France, and the evaluation of the gaps between these two actors of the AI employment value chain. The results of this analysis contribute to the theoretical corpus around AI by providing a refined vision of the categories of occupations related to this technology and the types of skills to operate in the discipline of AI. In fact, most previous studies adopted a generic perspective by analyzing the needs of the labour market in terms of IT skills, without paying particular attention to the emerging specificities of AI (e.g. [10-12]). The few studies that focused on this technology used an empirical approach based on interviews and survey questionnaires (e.g. [13, 14]). They mainly highlighted needs in terms of soft skills and did not identify the potential disparities between the professionals' requirements and the academic content. In contrast to this extant research, our approach covers a mass of data that is not limited to a particular sector and is based on an objective analysis that is independent of researchers' interpretation biases. Accordingly, we provide a better understanding of the skills needed to build an AI capability [15] at the individual level, but also at the organizational level by considering the types of professions required in firms to capitalize on AI. From a practical standpoint, this study establishes an overall picture of the AI labour market in France, which can be used to improve or build educational programs and guide individuals who wish to become AI professionals to prepare for the job market.

This paper is structured as follows. Section 2 is devoted to our theoretical foundation while section 3 explains our methodological approach. The results are then presented and discussed in section 4. Finally, this paper is concluded with its main implications, limitations and research perspectives.

\section{Theoretical foundations}

\subsection{Origins and evolution of $A I$}

The term Artificial Intelligence (AI) includes all the theories and techniques used to build machines capable of simulating human intelligence [16]. Table 1 describes the most important breakthroughs in AI research over time that we detail in the following paragraphs.

The birth of AI coincides with the appearance of computers in the 1940s and 1950s, the emergence of the theories of connectionism and cognitivism, and the discussions about the possibility of creating an artificial brain. Indeed, a memo by Warren Weaver [31] on automatic translation of languages suggested that a machine could very well perform a task that falls within the scope of human intelligence. Similarly, Alan Turing's article [18] explored the issue of determining whether a machine is conscious or not. The Turing Test, which evaluates the ability of a machine to hold a human conversation, is derived 
Table 1

Important advances in $\mathrm{AI}$ research over time

\begin{tabular}{|c|c|c|c|}
\hline Date & Breakthrough & Description & Reference \\
\hline 1943 & $\begin{array}{l}\text { Foundations of } \\
\text { neural networks }\end{array}$ & $\begin{array}{l}\text { Established by Warren McCulloch, which make analogies between the human brain and } \\
\text { computer machines. }\end{array}$ & [17] \\
\hline 1950 & Turing test & A test for a machine's intelligence and ability to trick humans into thinking it is human. & [18] \\
\hline 1956 & Birth of AI & $\begin{array}{l}\text { The term 'Artificial Intelligence' coined by John McCarthy during a conference at Dartmouth } \\
\text { college. }\end{array}$ & [19] \\
\hline 1961 & Unimate & The first industrial robot able to replace humans on the assembly line of General Motors. & [20] \\
\hline 1965 & ELIZA & $\begin{array}{l}\text { A pioneering chatbot created at the MIT Artificial Intelligence Laboratory by Joseph } \\
\text { Weizenbaum. }\end{array}$ & [21] \\
\hline $1970 \mathrm{~s}$ & AI winters & $\begin{array}{l}\text { Funds' suspension by American and British agencies for AI research following the Lighthill } \\
\text { report underlining AI's inability to deliver on promises. }\end{array}$ & [22] \\
\hline $1980 \mathrm{~s}$ & Expert Systems & $\begin{array}{l}\text { Revival of AI research projects thanks to the creation by Edward Feigenbaum of expert } \\
\text { systems able to emulate the decision-making ability of a human expert. }\end{array}$ & [23] \\
\hline 1997 & Deep Blue & A computer program by IBM that beat the world chess champion Gary Kasparov. & [24] \\
\hline 1999 & AIBO & The first robot pet dog designed by Sony, with personality and skills that develop over time. & [25] \\
\hline 2000 & Deep learning & $\begin{array}{l}\text { A class of machine learning algorithms introduced by Igor Aizenberg, that uses multiple } \\
\text { layers to progressively extract higher-level features from the raw input. }\end{array}$ & [26] \\
\hline 2005 & Stanley & $\begin{array}{l}\text { Creation by Stanford University in collaboration with Volkswagen of the first autonomous car } \\
\text { that won the DARPA grand challenge. }\end{array}$ & [27] \\
\hline 2011 & Watson & A computer program by IBM that won the first place in the $1 \mathrm{M} \$$ prize TV quiz show Jeopardy. & [28] \\
\hline 2014 & Personal assistants & $\begin{array}{l}\text { Use of speech recognition to answer questions and perform tasks (Siri, Alexa, Google now, } \\
\text { Cortana, etc.). }\end{array}$ & [29] \\
\hline 2017 & Alphago & $\begin{array}{l}\text { A computer program by Google that defeated the champions Lee Sedol and Ke Jie in Go, a } \\
\text { game with more possibilities than the number of atoms in the universe }\left(2^{170}\right) \text {. }\end{array}$ & [30] \\
\hline
\end{tabular}

from this article. The formalization of AI as a true scientific field dates back to 1956, during a conference organized in the United Sates at Dartmouth College [32]. Subsequently, this field reached prestigious universities such as Stanford and MIT.

In the mid-1960s, AI research was mainly funded by the US Department of Defense and concentrated in a few specialized laboratories around the world. In 1974, an "AI Winter" occurred as many experts failed to deliver their promises on AI development and applications. As a result, the British and American governments reduced their funding for research in this field [22]. In the 1980s, the success of the expert systems led to the revival of AI research projects. An expert system is a software that is capable of reproducing the cognitive mechanisms of a human expert in a particular field based on a set of rules. Due to this success, the AI market reached a value of one billion dollars, which has motivated different governments to financially support academic projects again [33]. The exponential development of computing performance according to Moore's Law made it possible, between 1990 and 2000, to exploit AI in previously uncommon areas such as mineral research or medical diagnosis. It was not until 1997 that a real media release took place when the famous AI Deep Blue created by IBM beat Garry Kasparov, the world chess champion [34].

Between 2000 and 2010, AI continued to grow with the development of connectivity and mobility, and the increased accessibility to personal computers, Internet, smartphones, etc. Since 2010, Moore's Law has been guiding the progress of AI, supported by data processing. Indeed, to perform a task, a system only needs rules: when it comes to thinking or delivering the right answer, it needs to learn. The problem of AI was no longer to have the brains for systems' development, but to have data to process. Thus, researchers developed new processes for Deep Learning which, fed by the data, achieved exceptional performance and enabled the launch diversified projects [35]. Today, data management allows AI to be applied to understand X-rays better than doctors, drive cars, do translation, play complex video games, create music, see through a wall, imagine a missing part of a photograph, etc. The fields where AI 
performs well are constantly growing, which raises many questions about the professional role of human beings in the future [36].

\subsection{AI market}

It is difficult to understand and grasp all areas of application for AI, because of their diversity and their overlapping. We therefore list the most common applications of AI today. This technology can be found in expert systems capable of simulating the behavior of a human expert who performs a specific task. AI is also widely used for the symbolic representation of knowledge in order to manipulate it through software. A third common application is Natural Language Processing (NLP) to understand a text independently of the language in which it is written [37]. AI additionally allows the resolution of complex problems found for example in games, and the recognition of speech, handwriting, or faces, for which neural networks are particularly efficient [38]. Finally, robotics is a dazzling use of AI with robots that react according to their environment, learn to recognize faces, follow moving objects and respond to sound and visual stimuli [39]. All of these applications are based on learning, as an algorithm or software should have autonomous learning capabilities to be considered intelligent [35].

The presence of these AI applications varies according to the company's sector of activity. Obviously, the sectors and processes that intensively use $\mathrm{AI}$ are those that generate the most data. We find it in the field of Marketing, especially for customer targeting, improving customer experiences using chatbot, and for e-commerce recommendation engines. AI is also used in Finance to perform high frequency trading, market analysis or even to develop advising robots. More specifically, in banking institutions, it can detect fraudulent transactions and calculate credit points to determine a customer's financial profile [40]. In addition, AI is strongly mobilized in social media to train neural networks to recognize faces and to moderate audiovisual content and comments [41]. Moreover, the medical sector increasingly integrates AI technologies for diagnosis by taking into account patients' history and allowing a better crossreferencing of medical specialties, or even for the automatic calculation of bone age from the X-ray of a hand [42]. The entertainment industry is also one of the biggest users of AI, which is integrated in gaming robots, augmented reality, and media content recommendation processes [38]. Finally, the recent emergence of IoT opens up the prospects for new uses of $\mathrm{AI}$ in home automation, farming, drones and autonomous cars [3].

Thus, AI techniques and their applications are constantly evolving and therefore require an evolution of professions. Indeed, several job positions are being transformed or completely replaced by AI technologies [9]. These include the professions of the past (e.g. assembly line workers, cashiers), those that are currently being automated (e.g. professional drivers, offshore professions) and those that will be automated later (health, auditing, etc.). In addition, the advent of $\mathrm{AI}$ is leading to the creation of new jobs related to algorithmic, emotional or data processing, such as Data Scientist, Big Data Developer or Data Manager [43]. Consequently, a major question arises concerning the readiness of academic institutions to train students in line with these rapid changes in the job market. However, no research performed an exhaustive analysis of the potential gap that exists between the needs of the recruiting firms and the skills developed in academic training focused on AI.

Few previous studies provided a partial answer to this question. On the one hand, the authors who performed a gap analysis focused on the IT sector as a whole including AI, but without providing a refined analysis of AI needs and skills. [11] studied the demand of IT professionals by exploring job offers and identified the most taught IT skills such as programming languages, databases and networks. [10] compared IT professional skills found in academic and professional literature, while [44] determined IT skill gaps from candidate profiles on social networks and job offers. On the other hand, studies that looked at skill requirements for $\mathrm{AI}$ in particular analyzed the needs of the job market without comparing them with the content of academic training. [45] used Latent Semantic Indexing to construct a taxonomy of Business Intelligence and Big Data skills from job offers. Other researchers used interviews and questionnaires to identify the skills required to be an AI professional $([13,14])$. They pointed out the soft skills needed, discussed the role of AI in IT education, and presented recommendations for the integration of $\mathrm{AI}$ in academic programs. The present research therefore complement these previous studies that provided a relative reading of AI skills needed by the job market. We propose to use a text mining approach that is independent of researchers' interpretation biases, to draw up an overview of recruiting firms' requirements in terms of AI competencies. We also carry out a comparison between these professional requirements and 
the content of academic training to formulate concrete proposals for adjusting the pedagogic offer in light of the emerging professions and the subsequent skills needed.

\section{Methodology}

To address our research question, we focused on the French AI training and job market for several reasons. On the one hand, France is very representative of this market. Regarding AI professionals, most of the major multinational players in this technology operate in French soil and the number of startups created around AI has increased by 38\% in 2019 [46]. Regarding AI training, France is a key player in the international academic market because of the high concentration of IT courses in schools and the partnerships they have developed with the international academic ecosystem [47]. On the other hand, France is particularly impacted by the changes brought by AI. Indeed, more than 2 million workers have to adapt their profiles and missions to the advances of this technology [9]. In addition, the rapid advent of AI induces important needs that the labour market struggles to meet [48], thus proving the inadequacy of academic training to the emerging AI professions. We explain in the following paragraphs our approach to collecting and analyzing academic contents and job offers related to AI.

\subsection{Data collection}

To extract the content of courses in France integrating AI, we identified the French engineering and business schools that offer such training. In this respect, we considered the Figaro rankings (Ranking of the best business schools in 2020 and the 2020 ranking of French engineering schools) and looked at whether each of these schools offered courses in AI. We then retrieved the brochures of the AI specialized curricula of these engineering and business schools. To allow a more refined analysis of training content in France, we also retrieved the syllabi of AI courses in these schools aside of specialized AI curricula. This process resulted in 33 extracted documents. Finally, we formatted them in .txt to enable their analysis by an algorithm.

For the extraction of the job offers, we chose the website www.indeed.fr as it is considered as the most complete and up-to-date database for job advertisements in France. Other platforms such as LinkedIn are often used by some firms as an additional means to broadcast the same offers posted on Indeed. We employed a script developed with Python to scrap the content of the selected website. The script allows to perform a job search with chosen keywords, in our case "Artificial Intelligence; AI; and/or Data Science" in French and English. To form an accurate dataset of job offers with the least possible redundancies, we scanned the entire site and made an extract for each month starting with June 2020 and comparing it with the preceding month. This approach showed that companies tend to repost the same job offers every one to three months in order to always appear in the first search results on the website and ensure better visibility to candidates. Therefore, we restricted the considered time span to March to June 2020, as it was the most appropriate interval to take into account the job market dynamics and avoid redundant job postings. The extracted data progressively fed a table with a job offer Id, its title and a description that concatenates all the available information about the offer. By going through the 307 job postings resulting from this process, we established that some of them corresponded to positions citing $\mathrm{AI}$ as a skill and not to $\mathrm{AI}$ occupations per se. As we are concerned by the second category in our research, we manually filtered the job offers as an automated analysis algorithm would have been inefficient given the small size of our sample. This process finally resulted in 281 job offers centered on AI.

\subsection{Data analysis}

To ensure consistency in the analysis, the content of the job and training offers in French has been translated into English via DeepL, a highly recommended translator using convolutional neural networks [49]. We relied on keyword extraction to analyze these contents. In this respect, we developed a Python code to process English text and identify its keywords based on NLP (Natural Language Processing). The NLP vectorizes the words and makes them understandable by an algorithm that can decipher, interpret and give meaning to human language. Our code analyzed all the words in the text, their frequency, their environment, their nature and function, and was able to produce the most relevant keywords as a result. This process allowed us to identify, within the training brochures and the job offers, elements associated with the level of training, its nature, and the listed skills. Finally, we manually sorted the extracted keywords because some of them remained incoherent, despite 


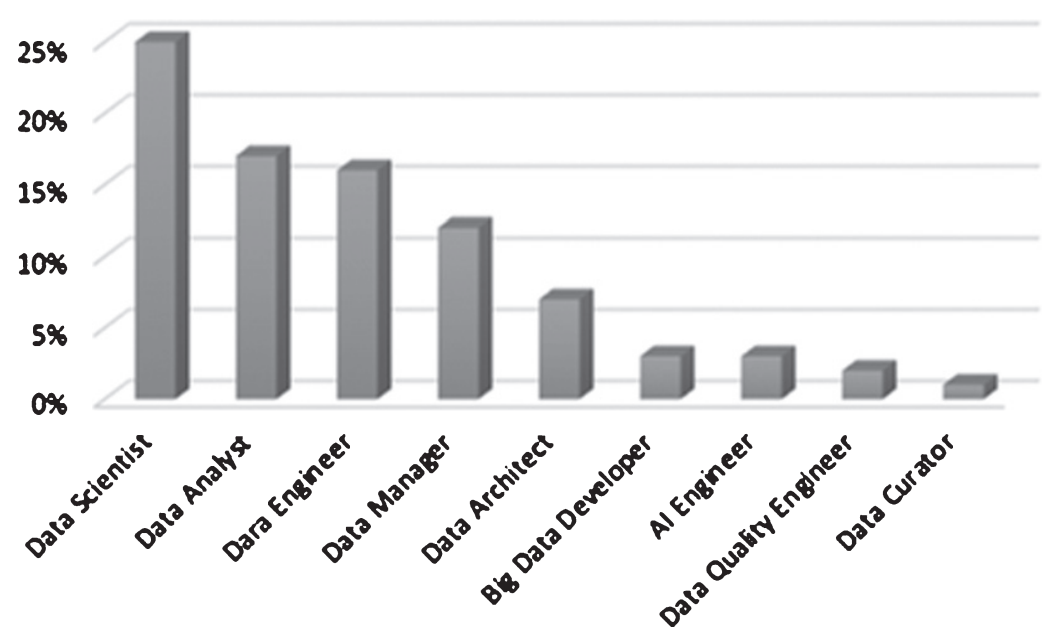

Fig. 1. Categories of AI professions.

our efforts to optimize the code. Indeed, the use of NLP is not perfect and sometimes leads to errors that must be managed humanely in post-processing.

In addition, we analyzed the titles of the job offers to identify the emerging professions in AI. We used an automated learning approach to filter the titles and classify them into categories. This approach consists of a textual categorization process, which automatically constructs a classifier by learning the characteristics of the content categories from a set of pre-classified documents [50]. We experimented several classifiers and concluded that the Support Vector Machine classifier was the most accurate.

\section{Results and discussion}

\subsection{Distribution of AI professions}

Our resulting classification of job offers (Fig. 1) on AI shows that Data Scientist is the profession that recruits the most (25\%). The latter designs programs to acquire, record, process and exploit massive data by crossing several sources thus making artificial learning effective. Then, two professions focusing on the upstream phases of the data value chain arrive at the second place ( 17\%): the Data Analyst who has a more restricted role than the Data Scientist because he is often limited to a certain type of data; and the Data Engineer who focuses on building the architecture and infrastructure for data generation. In the third place, we find the Data Manager (12\%) who has in-depth knowledge of the company's sector and the competition, and participates in strategic decision-making. Then, the Data Architect, who is responsible for making the choice between the different storage technologies, is required in $7 \%$ of the job offers. Finally, four other AI professions with strong technical connotations are very rarely found in job postings. These are the Big Data Developer who is proficient in various programming languages particularly Java and Python; the AI Engineer who focuses on the design of neural networks; the Data Quality Engineer whose role is to design and verify infrastructures of data quality control; and the Data Curator who focuses on metadata management and on identifying best practices for working with data.

\subsection{Comparison in terms of training peculiarities}

As depicted in Table 2, based on the keywords extracted from the job offers, we characterized the market prerequisites in terms of the nature of training. We concluded that firms most often require a candidate with a purely technical background (77\%). In a very rare cases, the advertisement stresses the need to have a dual engineer/manager background (1\%). No job offer is primarily focused on the candidate's managerial skills. The rest of the offers emphasizes the need for the candidate to have an engineering or a business school background (20\%). These results are aligned with the characteristics of the academic market. Indeed, our analysis of the training content showed that curricula centered on AI are present in $75 \%$ of engineering schools while such diplomas exist in $30 \%$ of business schools. This can be 
Table 2

The job market vs. the academic offer in terms of the training characteristics

\begin{tabular}{|c|c|c|}
\hline & Requirements of the job market & Peculiarities of the Academic offer \\
\hline Nature of training & $\begin{array}{l}\text { - Technical background required in } 77 \% \text { of job offers } \\
\text { - Dual engineer-manager in } 1 \% \text { of the offers } \\
\text { - Alumni of an engineering or a business school in } \\
20 \% \text { of the offers }\end{array}$ & $\begin{array}{l}\text { - AI centered curricula in engineering }(75 \%) \text { and } \\
\text { business schools ( } 30 \%) \\
\text { - AI courses for curricula not specialized on AI } \\
\text { proposed in engineering (20\%) and business schools } \\
(45 \%)\end{array}$ \\
\hline Level of training & $\begin{array}{l}\text { - Master degree in } 82 \% \text { of the job offers } \\
\text { - PhD in computer science in } 11 \% \text { of the offers } \\
\text { - Not specified in } 6 \% \text { of the offers (Most likely a Master } \\
\text { degree based on the content of the job postings) }\end{array}$ & $\begin{array}{l}\text { - Master degree in } 85 \% \text { of the AI centered curricula } \\
\text { - Bachelor and Master degrees not centered on AI and } \\
\text { including AI courses in } 33 \% \text { of the analyzed schools. }\end{array}$ \\
\hline
\end{tabular}

accounted for the fact that AI professionals must primarily possess technical skills to properly handle data and algorithms. Additionally, AI courses for curricula not specialized on AI are proposed in $20 \%$ of engineering and $45 \%$ of business schools. The keen interest of management institutions in the AI thematic can be explained by the need to familiarize their future alumni with use cases of this technology and its jargon in order to promote their dialogue with different professions within firms.

As for the level of training, the vast majority of job postings request a Master degree $(82 \%)$ due to the highly specific nature of the knowledge underlying the AI professions. Some job offers even require $\boldsymbol{a}$ PhD often in computer science (11\%). In a very rare cases $(6 \%)$, the level of training is not specified. However, the content of these offers does not suggest that candidates may have a level below the skills associated with at least a Master degree. These findings are overall consistent with the academic offers. Indeed, the majority of specialized AI curricula are Master degrees (85\%). Also, 33\% of the analyzed schools include AI courses in Bachelor and Master levels' curricula not centered on AI.

\subsection{Comparison in terms of skills}

Figure 2 summarizes the most frequent skills in the AI job advertisements while the overall skills that emerged from our analysis are introduced in Table 3. These skills can be divided into three categories namely Technical, Soft and Interdisciplinary skills. We analyze below the composition of these categories and compare them with the content of academic trainings.

First, Fig. 2 shows that technical skills are the most recurrent in job postings. They include the following five sub-categories:

- Programming languages are required in all job postings. The most requested is Python (73\%) followed by Java $(59 \%)$ and $C++(53 \%)$. This is consistent with the order of languages taught in schools where Python comes first (present in $90 \%$ of the analyzed curricula) and with the IEEE ranking [51]. Other programming languages are less required in the job market (R, Scala or $\mathrm{C \# )}$ and are also less present in training brochures.

- Secondly, all job offers highlight needs in terms of Data Science that differ according to the nature of the job in question. We often find Machine Learning and Deep Learning techniques $(82 \%)$ as well as skills that are part of the BI chain (57\%) such as Dashboarding, Data Visualization, and Datamart/Datawarehouse modeling. All of the analyzed academic curricula also include these skills.

- Thirdly, several job offers $(22 \%)$ stress the need to master specific tools such as Github, Microsoft Power BI, or Squash. Some even require methodological (ITIL, Design Thinking, Devops) and mathematical (Data Mining, Algorithmic Design, etc.) certifications (9\%). These tools and certifications constitute a significant gap in academic training content. Regarding the tools, their diversity compels schools to make trade-offs, which explains the absence of commonly taught tools. Therefore, academic institutions must be aware of the most prominent tools to integrate into their training content. As for certifications, the few schools that pay attention to them $(10 \%)$ only offer course content to prepare their students to pass the certification by their own means. Institutions could thus 


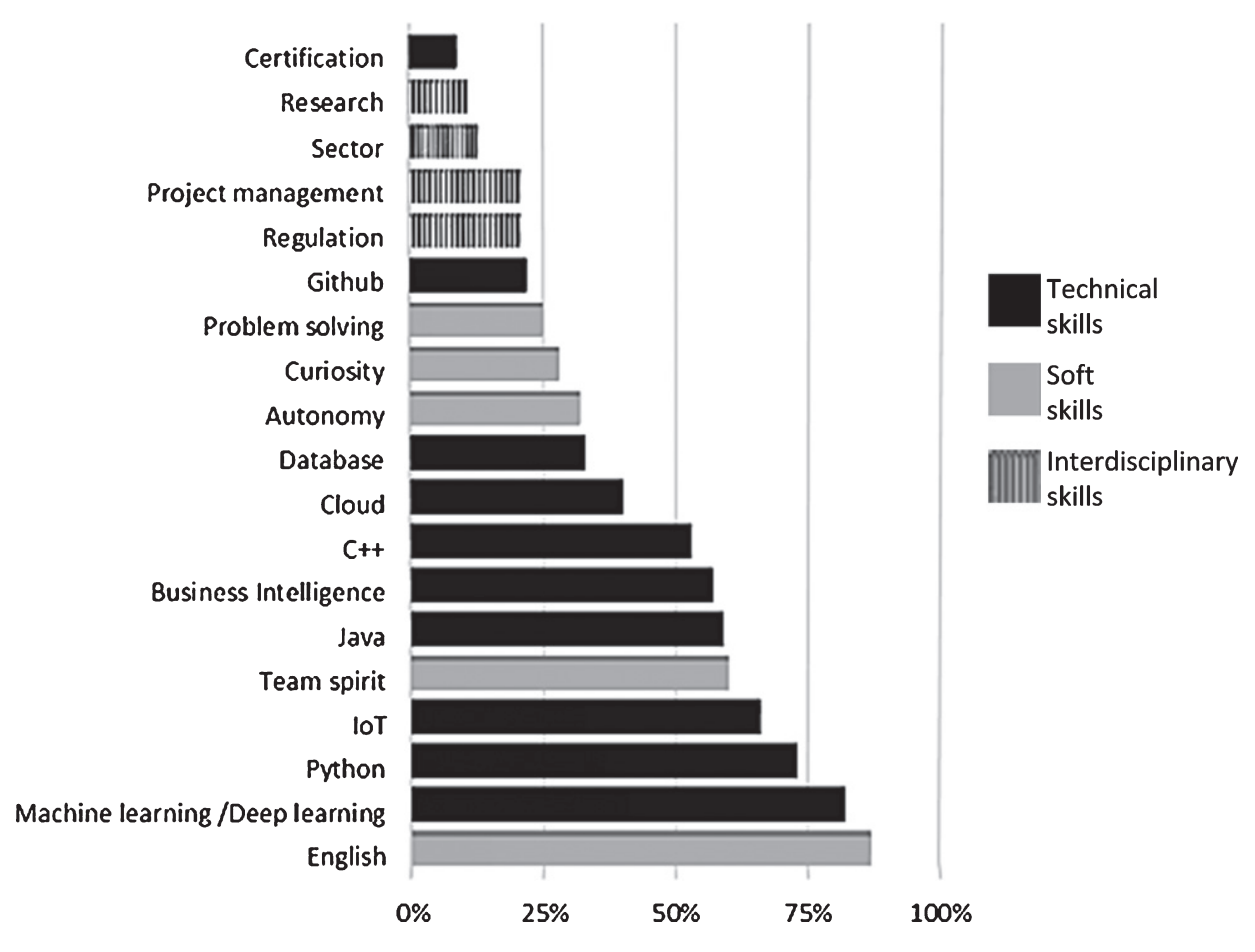

Fig. 2. Word frequencies in AI job offers.

establish partnerships with software and certifying organisms to meet these increasingly expressed needs of the AI labour market.

- The fourth category of technical skills corresponds to the mastery of technologies other than $A I$ such as IoT (66\%) or the cloud (40\%) given the interconnected nature of digital technologies. Generally, schools build curricula around AI that take into account the close links between these technologies and communicate on this asset of their training through their brochures.

- Finally, job offers abound with a plethora of technical skills parallel to AI including prototyping, modeling, optimization, econometrics, but especially databases. Candidates are required to master relational databases SQL and NoSQL (33\%), and query languages such as hive, pig and squirel (13\%). Academic offers in $\mathrm{AI}$ also include courses related to databases (70\%). When the content is explicitly specified in the brochures, it is often Oracle or SQL server.

In addition to technical skills, the majority of job offers require soft skills that can be divided into two sub-categories:

- The most frequently cited prerequisites are related to the modus operandi, in particular team spirit (60\% of the offers), autonomy (32\%), curiosity (28\%) and problem solving (25\%). Our analysis of the training offers shows that schools explicitly communicate in their brochures and syllabi on teamwork skills ( $79 \%$ of the extracted documents). The absence of other soft skills in these documents would be due to two reasons. On the one hand, the acquisition of most of these skills depends on each learner's initiative to prepare for entering the job market. On the other hand, academic curricula include several activities that tacitly promote learners' autonomy, curiosity and creativity among others.

- Then, the job offers underline prerequisites in terms of the ability to work in an international context. This aptitude of the students can be fostered by the schools' establishment of international partnerships for academic exchanges, which exist in $52 \%$ of the academic curricula focused on AI. The international orientation of the AI market is even noticeable through the language skills required in job offers where English 
Table 3

Overview of Skills required by the AI Job Market

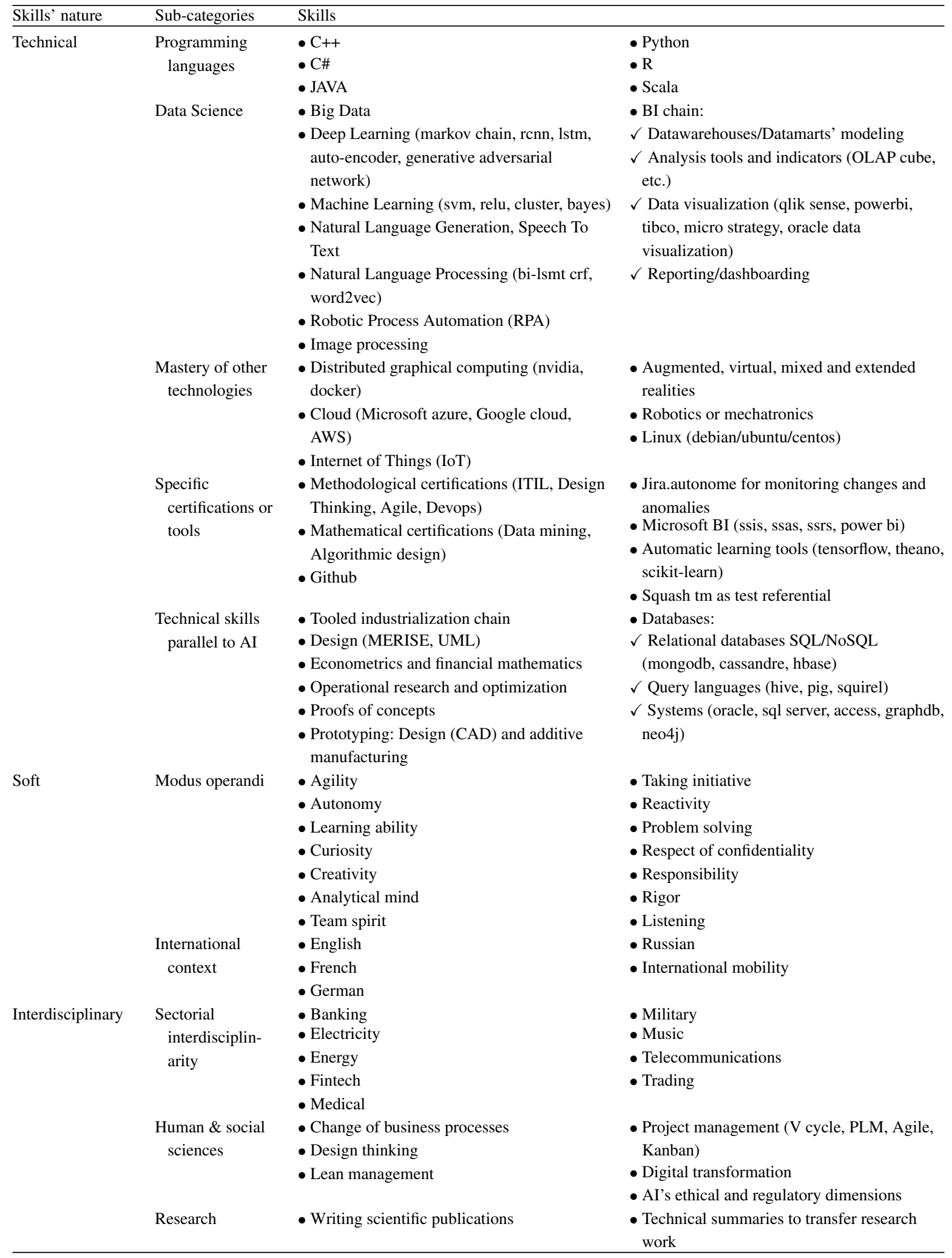


is ubiquitous (87\%). English is indeed necessary to adapt to the rapid changes in AI. This language skill is otherwise present in all AI training brochures.

Finally, our analysis highlighted the need for three sub-categories of interdisciplinary competencies with respect to $\mathrm{AI}$ :

- Several job offers require the candidate to be familiar with the specificities of the activity sectors $(13 \%)$ including energy, music, medical or military. This sectorial inter-disciplinarity is not visible in academic training brochures. Schools must therefore think about pedagogical modalities to allow students grasp this property of AI through use cases related to several sectors. For example, the students may learn data collection and the use of AI to interpret this data, by working closely with companies that would benefit from the analyses performed by the student. At the same time, the student will develop a sense of listening, responsibility and responsiveness.

- Then, we found interdisciplinary skills related to the human and social sciences required in $21 \%$ of job postings. These include ethical and regulatory dimensions, project management, design thinking, change management and lean management. While these skills are clearly highlighted in the brochures of business schools, they are less present in engineering curricula. Indeed, technical skills are a priority for these graduates in order to operate effectively in the various AI professions. However, engineering schools must also ensure that students develop managerial skills to better apprehend these emerging technologies and support their responsible implementation in organizations.

- Finally, we were surprised by the fact that $11 \%$ of the job offers require research skills, for instance the writing of scientific articles and technical syntheses for scientific outreach. Only two academic brochures (6\% of the analyzed documents related to training) explicitly emphasize a pedagogical content on research. Schools could therefore consider integrating into their curricula courses on research methodologies but also establish partnerships with companies and laboratories to implement learning by doing of students around themes with scientific and pragmatic implications [52].

\section{Conclusions, implications and perspectives}

Technological advances in AI are revolutionizing firms' activities and giving rise to specific skill requirements. The purpose of this study was to analyze the extent to which higher education is responding to the emerging needs in terms of skills for the AI labour market. Our results suggest that the competencies required to operate in AI fall within three categories: technical, interdisciplinary and soft skills. For the technical skills, there is an overall balance between academic courses and job offers in Data Science, programming languages, mastery of digital technologies and of parallel techniques such as databases. Nevertheless, schools should strive to certify their graduates and to ensure their mastery of the tools that are highly demanded by the job market. We also noted a gap in terms of interdisciplinary skills, namely research and sectoral knowledge in all curricula, and human and social sciences specifically within engineering schools. Therefore, institutions must invest in the development of these skills among their students as well as in the expansion of their cognitive abilities. In particular, technical programs must sensitize students to the ethical and regulatory issues of AI to enable its responsible implementation. These results help advancing both academic and practical knowledge and provide avenues for future research as explained below.

\subsection{Theoretical implications}

From a theoretical standpoint, we complement prior studies that examined some skills acquired by students enrolled in AI [53] and IT programs ([54, 55]) by providing an overview of emerging professions centered on $\mathrm{AI}$ and a categorization of the skills required to operate in this field. Our results would guide graduates towards some of the most critical competencies in the $21^{\text {st }}$ century [56], particularly by helping them build an AI capability [15] at the individual level. This study also supports the establishment of such capability at the organizational level by raising companies' awareness of AI professions and the combination of skills that should be developed internally through employees' engagement and reciprocity [57] as well as top management support in order to capitalize on this emerging technology.

\subsection{Practical implications}

From a practical standpoint, this research first helps higher education institutions to align academic 
training on AI with the job market needs [58] and provides educators with an overview of the critical skills that they should strive to reach as learning outcomes of their courses [59]. Our results would also promote the integration of graduates in the job market by sensitizing them to the AI related competencies they need to develop even autonomously to fill potential gaps in their academic curricula. In addition, through this interdisciplinary study, companies can be informed on the important AI skills and occupations regardless of the operating sectors, thus allowing a cross-fertilization of good practices. At the country level, the present research may help French institutions to develop constructive partnerships for AI programs with other developed countries whose AI labour markets possess similar dynamics. These partnerships should be established to allow students acquire the skills lacking in their training within their original institutions. By applying a similar analysis at the level of each partnering country, it would be possible to build an educational ecosystem around AI among developed countries that promotes their complementarity by enabling students access country-specific sets of skills through academic exchanges. Our results can also be beneficial to developing countries to optimize their construction of school programs in AI and the organization of the labour market in order to capitalize on the contributions of this technology.

\subsection{Limitations and future research avenues}

This study has several limitations that pave the way for future research. In fact, it would be interesting to conduct a refined analysis of our sample in order to establish a breakdown of skill requirements by level of experience and by profession category. Then, our sample can be expanded in three ways to yield new results. Firstly, the analysis can cover international AI courses that constitute an input of competencies for students in France as several schools established academic partnerships internationally. Secondly, the scope can be extended by including university Master and Doctorate level programs that represent a significant part of future AI recruits. Thirdly, it would be interesting to include in the sample of job offers those in the IT field integrating AI but that do not constitute jobs centered on this technology. This will raise awareness of other academic training in IT to the interdisciplinary nature of $\mathrm{AI}$ and promote its integration into these curricula. A last limitation concerns our translation from French to English of job offers and academic training content to ensure a consistent analysis. This step, although essential, can lead to errors and thus to misunderstandings or inconsistencies in the analysis algorithm. We used DeepL for translation which relies on convolutional neural networks and is highly recommended for this kind of application. It would be interesting to deepen the work by mobilizing other translators and comparing the results.

\section{Acknowledgments}

The authors have no acknowledgments.

\section{Author contributions}

CONCEPTION: Lamiae Benhayoun and Daniel Lang

METHODOLOGY: Lamiae Benhayoun

DATA COLLECTION: Lamiae Benhayoun

INTERPRETATION OR ANALYSIS OF DATA:

Lamiae Benhayoun and Daniel Lang

PREPARATION OF THE MANUSCRIPT: Lamiae

Benhayoun

REVISION FOR IMPORTANT INTELLECTUAL CONTENT: Lamiae Benhayoun and Daniel Lang SUPERVISION: Lamiae Benhayoun and Daniel Lang

\section{References}

[1] Zahra SA, George G. Absorptive capacity: A review, reconceptualization, and extension. Acad Manag Rev. 2002; 27(2):185-203.

[2] Mariani MM, Fosso Wamba S. Exploring how consumer goods companies innovate in the digital age: The role of big data analytics companies. J Bus Res. 2020;121:338-52.

[3] Reis C, Ruivo P, Oliveira T, Faroleiro P. Assessing the drivers of machine learning business value. J Bus Res. 2020;117:232-43.

[4] von Krogh G. Artificial Intelligence in Organizations: New Opportunities for Phenomenon-Based Theorizing. Vol. 4, Academy of Management Discoveries. Academy of Management Discoveries; 2018. pp. 404-409.

[5] Davenport TH, Ronanki R. Artificial intelligence for the real world. Harv Bus Rev. 2018;January-February 2018(1): 108-16.

[6] Shahzad IA, Farrukh M, Wu Y, Trunk N. Human systems management: A retrospective of 40 years. Hum Syst Manag. 2021;40(1):15-30.

[7] Wamba-Taguimdje SL, Fosso Wamba S, Kala Kamdjoug JR, Tchatchouang Wanko CE. Influence of artificial intel- 
ligence (AI) on firm performance: the business value of AI-based transformation projects. Bus Process Manag J. 2020;26(7):1893-924.

[8] Wilson HJ, Daugherty PR, Morini-Bianzino N. The jobs that artificial intelligence will create. MIT Sloan Manag Rev. 2017;58(4):14-6.

[9] Kilbride J. IBM Study: The Skills Gap is Not a Myth, But Can Be Addressed with Real Solutions. IBM Newsroom [Internet]. 2019; Available from: https://newsroom.ibm. com/2019-09-06-IBM-Study-The-Skills-Gap-is-Not-aMyth-But-Can-Be-Addressed-with-Real-Solutions

[10] Huang H, Kvasny L, Joshi KD, Trauth E, Mahar J. Synthesizing IT job skills identified in academic studies, practitioner publications and job ads. In: SIGMIS CPR'09 Proceedings of the 2009 ACM SIGMIS Computer Personnel Research Conference. 2009. pp. 121-7.

[11] Koong KS, Liu LC, Net FYI. A Study of the Demand for Information Technology Professionals in Selected Internet Job Portals. J Inf Syst Educ. 2002;13(1):21-8.

[12] Litecky C, Igou AJ, Aken A. Skills in the management oriented IS and enterprise system job markets. In: SIGMISCPR' 12 - Proceedings of the 2012 Computers and People Research Conference. 2012. pp. 35-43.

[13] Bolton C, Machová V, Kovacova M, Valaskova K. The power of human-Machine collaboration: Artificial intelligence, business automation, and the smart economy. Econ Manag Financ Mark. 2018;13(4):51-6.

[14] Santos S, Freire C, Barbosa I, Figueiredo H, Costa MJ. Assessing Transversal Competencies for the Future of Graduate Work: an Adaptation of the Multiple Mini-Interviews Method. In: ICERI2020 Proceedings. 2020. pp. 4112-22.

[15] Mikalef P, Fjørtoft SO, Torvatn HY. Developing an Artificial Intelligence Capability: A Theoretical Framework for Business Value. In: Lecture Notes in Business Information Processing. Cham: Springer; 2019. pp. 409-16.

[16] Russell Stuart J, Norvig P. Artificial intelligence: a modern approach. Prentice Hall;

[17] McCulloch WS, Pitts WH. A logical calculus of the ideas immanent in nervous activity. Syst Res Behav Sci A Sourceb. 2017;5(4):93-6.

[18] Turing IBA. Computing machinery and intelligence-AM Turing. Mind. 59(236):433.

[19] McCarthy J, Minsky ML, Rochester N, Shannon CE. Dartmouth Artificial Intelligence Project Proposal. University of Stanford;

[20] O'Regan G. Unimation. In: Pillars of Computing. Cham: Springer; pp. 219-223.

[21] Weizenbaum J. ELIZA-A Computer Program For the Study of Natural Language Communication Between Man And Machine. Commun ACM. 1983;26(1):23-8.

[22] Floridi L. AI and Its New Winter: from Myths to Realities. Vol. 33, Philosophy and Technology. Philosophy and Technology; 2020. pp. 1-3.

[23] Feigenbaum EA. Expert systems in the 1980s. State of the art report on machine intelligence. Maidenhead: PergamonInfotech;

[24] Tan CJ. Deep blue: Computer chess and massively parallel systems. Proc Int Conf Supercomput. 1995;Part F129361 (1-2):237-9.

[25] Fujita M. AIBO: Toward the era of digital creatures. Int J Rob Res. 2001;20(10):781-94.
[26] Aizenberg IN, Aizenberg NN, Vandewalle J. MultiValued and Universal Binary Neurons: Theory, Learning, and Applications. IEEE Trans Neural Networks. 2001; 12(3):647.

[27] Thrun S, Montemerlo M, Dahlkamp H, Stavens D, Aron A, Diebel J, et al. Stanley: The robot that won the DARPA Grand Challenge. Springer Tracts Adv Robot [Internet]. 2007;36(9):1-43. Available from: http://link.springer.com/ chapter/10.1007/978-3-540-73429-1_1

[28] Markoff J. Computer Wins on 'Jeopardy!': Trivial, It's Not. New York Times [Internet]. 2011;16:A1. Available from: http://www.nytimes.com/2011/02/17/science/17jeopardywatson.html?ref=us

[29] Bellegarda JR. Spoken Language Understanding for Natural Interaction: The Siri Experience. Nat Interact with Robot Knowbots Smartphones. 2014;3-14.

[30] Graepel T. AlphaGo - Mastering the game of go with deep neural networks and tree search. Lect Notes Comput Sci (including Subser Lect Notes Artif Intell Lect Notes Bioinformatics). 2016;9852 LNAI(7587):XXI.

[31] Weaver W. The mathematics of communication. Commun Theory Second Ed. 2017;181(1):27-38.

[32] Kline RR. Cybernetics, automata studies, and the dartmouth conference on artificial intelligence. IEEE Ann Hist Comput. 2011;33(4):5-16.

[33] McLeod R, Schell GP. Management information systems. 2007; USA: Pearson/Prentice Hall.

[34] Haenlein M, Kaplan A. A brief history of artificial intelligence: On the past, present, and future of artificial intelligence. Calif Manage Rev. 2019;61(4):5-14.

[35] Meng T, Jing X, Yan Z, Pedrycz W. A survey on machine learning for data fusion. Inf Fusion. 2020;57:115-29.

[36] Wogu IAP, Katende JO, Elegbeleye A, Roland-Otaru CO, Apeh HA, Ifeanyi-Reuben NJ, et al. Artificial Intelligence, Other Minds, and Human Factor Development: The Fate of Man in the World of Machines. In: Handbook of Research on the Role of Human Factors in IT Project Management. IGI Global; pp. 205-220.

[37] Pandey VK, Rajput P. Review on natural language processing. J Crit Rev. 2020;7(10):1170-4.

[38] Fraser J, Papaioannou I, Lemon O. Spoken conversational AI in video games - Emotional dialogue management increases user engagement. In: Proceedings of the 18th International Conference on Intelligent Virtual Agents, IVA 2018. 2018. pp. 179-84.

[39] Scheppler B, Weber C. Robotic Process Automation. Vol. 43, Informatik-Spektrum. Springer; 2020. pp. 152-156.

[40] Zafar MAA, AIH HMA. Service Quality, Customer Satisfaction and Loyalty: An Empirical Analysis of Banking Sector in Pakistan. Inf Manag Bus Rev. 2012;4(4):159-67.

[41] Choi JY, De Neve W, Plataniotis KN, Ro YM. Collaborative face recognition for improved face annotation in personal photo collections shared on online social networks. IEEE Trans Multimed. 2011;13(1):14-28.

[42] Park SH, Han K. Methodologic guide for evaluating clinical performance and effect of artificial intelligence technology for medical diagnosis and prediction. Radiology. 2018;286(3):800-9.

[43] Fountaine T, McCarthy B, Saleh T. Building the AI-powered organization. Harv Bus Rev. 97(4):62-73. 
[44] Malherbe E, Aufaure MA. Bridge the terminology gap between recruiters and candidates: A multilingual skills base built from social media and linked data. In: Proceedings of the 2016 IEEE/ACM International Conference on Advances in Social Networks Analysis and Mining, ASONAM 2016. IEEE; 2016. pp. 583-90.

[45] Debortoli S, Müller O, Vom Brocke J. Comparing business intelligence and big data skills: A text mining study using job advertisements. Bus Inf Syst Eng. 2014;6(5):289-300.

[46] Roland Berger. Joining the dots - A map of Europe's AI ecosystem. Fourth "France is AI" Conf Stn F. 2018;1-20.

[47] Rasinen A. An analysis of the technology education curriculum of six countries. Vol. 15, Journal of Technology Education. 2003. pp. 31-47.

[48] Laville B, Hierso G, Vienne G. Responsabilité numérique des entreprises. 1. L'enjeu des données. Rapport Public pour France Stratégie;

[49] Isabelle P, Kuhn R. A challenge set for french $\longrightarrow$ English machine translation. arXiv. 2018.

[50] Kowsari K, Meimandi KJ, Heidarysafa M, Mendu S, Barnes L, Brown D. Text classification algorithms: A survey. arXiv. 2019;10(4):150.

[51] IEEE Spectrum. The Top Programming Languages. IEEE Spectr [Internet]. 2021;31. Available from: https://spec trum.ieee.org/computing/software/the-top-programminglanguages-2019

[52] Ashraf RU, Hou F, Kirmani SAA, Ilyas M, Zaidi SAH, Ashraf MS. Student employability via university-industry linkages. Hum Syst Manag. 2018;37(2):219-32.
[53] Chatterjee S, Bhattacharjee KK. Adoption of artificial intelligence in higher education: a quantitative analysis using structural equation modelling. Educ Inf Technol. 2020; 25(5):3443-63.

[54] Djikhy S, Moustaghfir K. International faculty, knowledge transfer, and innovation in higher education: A human resource development perspective. Hum Syst Manag. 2019; 38(4):423-31.

[55] Popescu S, Santa R, Teleaba F, Ilesan H. A structured framework for identifying risks sources related to human resources in a 4.0 working environment perspective. Hum Syst Manag. 2020;39(4) :511-27.

[56] Rakowska A, de Juana-Espinosa S. Ready for the future? Employability skills and competencies in the twenty-first century: The view of international experts. Hum Syst Manag. 2021;Preprint:1-16.

[57] Ahmed T, Khan MS, Thitivesa D, Siraphatthada Y, Phumdara T. Impact of employees engagement and knowledge sharing on organizational performance: Study of HR challenges in COVID-19 pandemic. Hum Syst Manag. 2020;39(4):589-601.

[58] Pence HE. Artificial Intelligence in Higher Education: New Wine in Old Wineskins? J Educ Technol Syst. 2019;48(1): $5-13$.

[59] Zawacki-Richter O, Marín VI, Bond M, Gouverneur F. Systematic review of research on artificial intelligence applications in higher education - where are the educators? Int J Educ Technol High Educ. 2019;16(1):1-27. 